\title{
Mechanical Anastomotic Coupling Device versus Hand-sewn Venous Anastomosis in Head and Neck Reconstruction-An Analysis of 1694 Venous Anastomoses
}

\author{
Rajan Arora ${ }^{1, \odot}$ Kripa Shanker Mishra ${ }^{1, \odot}$ Hemant T. Bhoye ${ }^{1} \quad$ Ajay Kumar Dewan ${ }^{1}$ \\ Ravi K. Singh ${ }^{1, \oplus}$ Ravikiran Naalla ${ }^{1}$ \\ ${ }^{1}$ Reconstructive Microsurgery Unit, Department of Surgical \\ Oncology, Rajiv Gandhi Cancer Institute and Research Centre, New \\ Delhi, India \\ Address for correspondence Ravikiran Naalla, MS, MCh, \\ Reconstructive Microsurgery Unit, Department of Surgical \\ Oncology, Rajiv Gandhi Cancer Institute and Research Centre, Room \\ no- 3064, Sir Chotu Ram Marg, Sector - 5, Rohini Institutional Area, \\ Rohini, New Delhi, Delhi - 110085, India \\ Indian J Plast Surg 2021;54:118-123. \\ (e-mail: ravi_2488@yahoo.co.in).
}

\author{
Abstract \\ Keywords \\ - microsurgery \\ - microvascular cou- \\ pling device \\ - free tissue transfer \\ - free flaps \\ - venous anastomosis \\ - microvascular \\ anastomosis \\ - technique \\ - head and neck \\ reconstruction
}

Background There is a steep learning curve to attain a consistently good result in microvascular surgery. The venous anastomosis is a critical step in free-tissue transfer. The margin of error is less and the outcome depends on the surgeon's skill and technique. Mechanical anastomotic coupling device (MACD) has been proven to be an effective alternative to hand-sewn (HS) technique for venous anastomosis, as it requires lesser skill. However, its feasibility of application in emerging economy countries is yet to be established.

Material and Method We retrospectively analyzed the data of patients who underwent free-tissue transfer for head and neck reconstruction between July 2015 and October 2020. Based on the technique used for the venous anastomosis, the patients were divided into an HS technique and MACD group. Patient characteristics and outcomes were measured.

Result A total of 1694 venous anastomoses were performed during the study period. There were 966 patients in the HS technique group and 719 in the MACD group. There was no statistically significant difference between the two groups in terms of age, sex, prior radiotherapy, prior surgery, and comorbidities. Venous thrombosis was noted in 62 (6.4\%) patients in the HS technique group and $7(0.97 \%)$ in the MACD group $(p=0.000)$. The mean time taken for venous anastomosis in the HS group was $17 \pm 4$ minutes, and in the MACD group, it was $5 \pm 2$ minutes ( $p=0.0001)$. Twenty-five $(2.56 \%)$ patients in the HS group and $4(0.55 \%)$ patients in MACD group had flap loss $(p=0.001)$.

Conclusion MACD is an effective alternative for $\mathrm{HS}$ technique for venous anastomosis. There is a significant reduction in anastomosis time, flap loss, and return to operation theater due to venous thrombosis. MACD reduces the surgeon's strain, especially in a high-volume center. Prospective randomized studies including economic analysis are required to prove the cost-effectiveness of coupler devices.
DOI https://doi.org/ $10.1055 / \mathrm{s}-0041-1731622$ ISSN 0970-0358 (c) 2020. Association of Plastic Surgeons of India.

This is an open access article published by Thieme under the terms of the Creative Commons Attribution-NonDerivative-NonCommercial-License, permitting copying and reproduction so long as the original work is given appropriate credit. Contents may not be used for commercial purposes, or adapted, remixed, transformed or built upon. (https://creativecommons.org/licenses/by-nc-nd/4.0/).

Thieme Medical and Scientific Publishers Pvt. Ltd. A-12, 2nd Floor, Sector 2, Noida-201301 UP, India 


\section{Introduction}

Free flaps facilitate better postoperative outcomes and are a superior choice of reconstruction modality for head and neck oncologic defects. ${ }^{1}$ The flap success rate at many major microsurgery centers is $>95 \% .{ }^{2}$ In a pursuit to decrease the complication rates and improve the flap survival rate, reconstructive surgeons have imbibed various strategies throughout their careers. One such technological advancement is a mechanical anastomotic coupler device (MACD) for venous anastomosis. Since its first description by Nakayama in 1962, the MACD has evolved to improve the patency of venous anastomosis and the reproducibility of results. The advantages of the MACD over the hand-sewn (HS) anastomosis are better vessel wall eversion and intima contact, rigid external stenting effects which prevent vessel spasm, fewer chances of intima tears, and absence of the foreign body in the vessel lumen.

Although MACD has been proved to be an effective alternative to the HS technique in terms of outcomes and reduction of the overall cost of the procedure, there is a limited number of studies comparing both groups in head and neck reconstruction. ${ }^{34}$ In addition to this, there is very limited data from the emerging economy countries, and its feasibility of integration into day-to-day practice is yet to be established. The primary aim of our study was to compare the efficacy of MACD versus HS technique in terms of venous thrombosis and flap failure rate. The secondary aim was to share our perspective on MACD from a high volume tertiary oncologic referral center from an emerging economy.

\section{Material and Methods}

This is a retrospective comparative study of all patients who underwent free flaps for reconstruction of head and oncologic defects between July 2015 and October 2020. We analyzed the patient's records for demographic data and operative details such as the location of the oncologic defects, flaps performed, size of the coupler, and complications. All patients who underwent single venous anastomosis per flap were included in the study. In patients who underwent two simultaneous free flaps, the anastomoses were counted separately. Patients were divided into the HS technique group (prior to March 2018) and the MACD group (after March 2018). We used 8-0 or 9-0 nylon sutures for an end-to-end or end-to-side venous anastomosis in HS technique group and MCAD by Synovis, Micro Companies Alliance, Inc, USA in the other group ( - Fig. 1). Although the coupler devices are available from 1 to $4 \mathrm{~mm}$. We have used only couplers of 2 to $4 \mathrm{~mm}$ size, as the smaller diameter MACD might be associated with a higher thrombosis rate. ${ }^{5}$ The two senior authors performed venous anastomosis in either group from a single institution. Artery anastomosis was performed first, followed by venous anastomosis. On a case-to-case basis, when the flap is congested after a single venous anastomosis, the second vein was anastomosed.

The primary outcomes of interest were total anastomotic time, venous thrombosis rate, and flap loss rate. Total anastomotic time implies time taken from the end

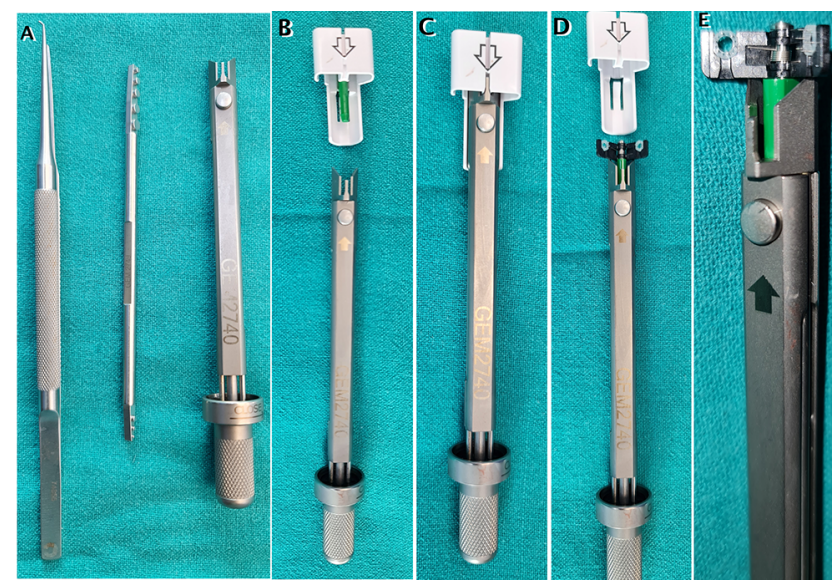

Fig. 1 Image showing mechanical anastomotic coupling device (MACD) (A) Coupler forceps, double-ended vessel measuring gauge, reusable anastomotic instrument. (B-D) Loading of coupler device on to the anastomotic instrument, (E) Coupler device ready for use.

of adventitial trimming to completion of the anastomosis. Venous thrombosis was defined as thrombosis at the anastomotic site, necessitating anastomotic revision or a second vein anastomosis.MACD anastomosis technique (-Fig. 2): The basic principle of anastomosis is applied to the coupler technique too. After adventitia trimming, donor and recipient veins are examined to rule out twisting. The coupler's size is determined with the vessel sizer by putting it close to the vein end. The coupler's size should be equal to the outer diameter of the veins, so that it can be pulled out easily through the ring. The donor vein is secured first because of its greater freedom, and then the device is moved toward the recipient vein, which is relatively immobile. The edges of the vessel wall are then everted over the rings' sharp pins to fix them on it. After fixing both ends, both the rings are brought together and are pressed against each other with a hemostat to fuse them firmly. Rings, with the completed anastomosis, are then detached from the device. In cases where the discrepancy in the diameter of the vein was minimal, we chose a smaller sized coupler. But when the difference was more, we preferred doing end-to-side anastomosis of a flap vein to a larger recipient vein in the neck, for example, internal jugular vein (IJV). The size of the coupler was chosen as per the size of the smaller vein. In the event of venous thrombosis, the revision of venous anastomosis was done by the HS technique. Following thrombosis, the vessel walls are inflamed and thickened, and it is difficult to evert the vessel wall over the coupler ring. We expressed continuous variables as mean \pm standard deviation (SD). Categorical variables are shown as the number and their respective percentage. An independent $t$-test has been used to compare the time between hand sewn and coupler group. Chi-square test is used to compare venous thrombosis between two groups. All data entries and statistical analyses have been performed using SPSS Version 23.0 software. All the $p$-values reported are two-sided, and $p$ values less than 0.05 are considered to indicate statistical significance. 

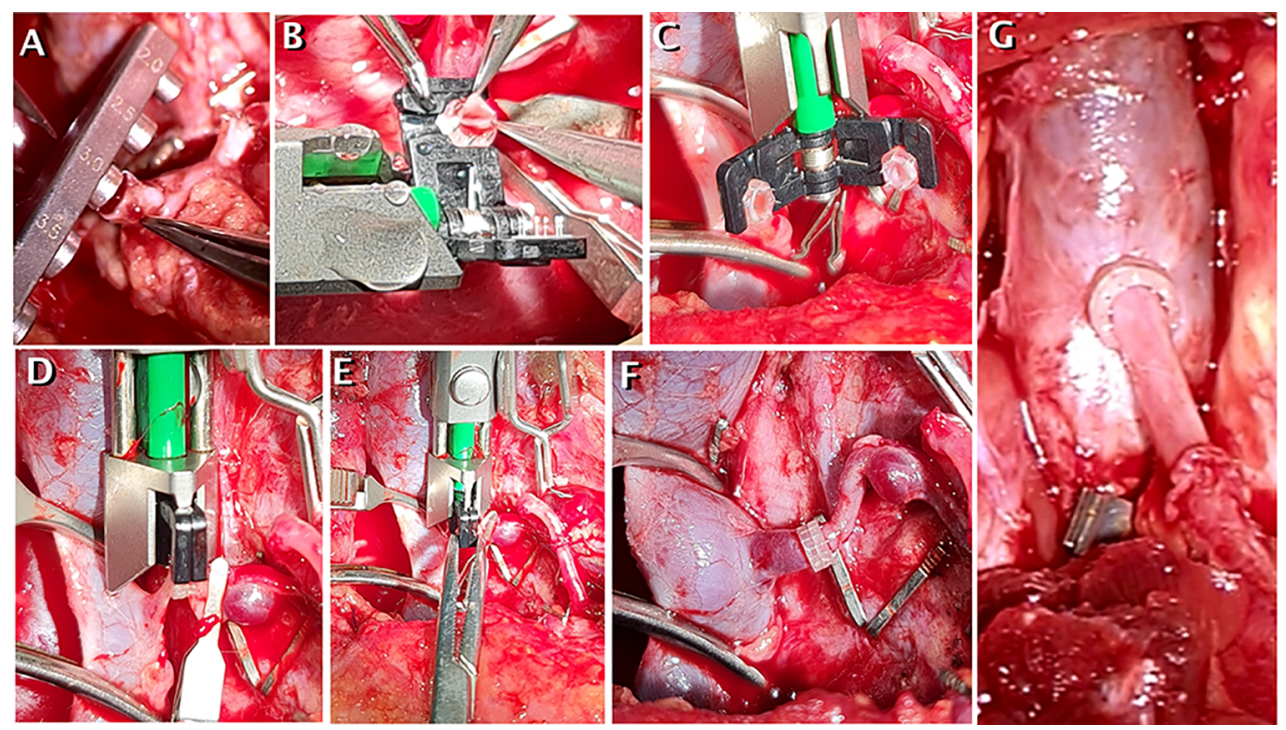

Fig. 2 Image showing steps of mechanical anastomotic coupling device (MACD) application (A) Measuring the diameter of vein (B) Eversion of donor vein wall onto the coupler device rings (C) Completion of impingement of both donor and recipient vein wall edges on to the coupler device pins (D) Closure of the jaws of coupler device (E) Ensuring the approximation of both jaws with a hemostat (F) Disengagement of the anastomotic instrument and completion of the end to end anastomosis (G) An image of end-to-side anastomosis performed similarly (the head end is at the superior aspect of the image).

\section{Results}

From July 2015 till October 2020, we performed 1694 venous anastomoses. Nine hundred and sixty-six patients underwent 975 venous anastomoses in the HS technique group. Seven hundred and nineteen patients underwent 719 anastomoses in the MACD group. Tumor size was T2 (43.6\%), T4 (34.9\%), and $\mathrm{T} 3(16.1 \%, \mathrm{~T} 1$ (5.4\%) in the study population. There was no significant difference between the two groups in terms of age, sex, prior radiotherapy/surgery, and comorbid illnesses. A detailed comparison of patient characteristics is made in - Table 1. Buccal mucosa, lower alveolus, and the tongue were the most common sites of the malignancy. The location of the malignancy in either group is shown in - Table 2. Anterolateral thigh flap (ALT), fibula flap, and radial artery forearm flap (RAFF) are the most commonly used flaps in either group (-Table 3 ). The most commonly

Table 1 Comparison of patient characteristics in HS technique and MACD group

\begin{tabular}{|c|c|c|c|}
\hline Characteristic & HS technique & MACD & $p$ value \\
\hline Mean age (years) & 49.8 & 51.2 & 0.15 \\
\hline Male & 849 & 604 & \multirow[t]{2}{*}{0.022} \\
\hline Female & 117 & 115 & \\
\hline Prior radiotherapy & 87 & 82 & 0.092 \\
\hline Prior neck surgery & 74 & 70 & 0.117 \\
\hline \multicolumn{4}{|c|}{ Comorbid illness } \\
\hline Diabetes mellitus & 232 & 146 & 0.088 \\
\hline Hypertension & 242 & 190 & 0.453 \\
\hline Cardiac disease & 72 & 59 & 0.531 \\
\hline
\end{tabular}

Abbreviations: HS, hand-sewn; MACD, mechanical anastomotic coupler device.
Table 2 Site of malignancy in the study population

\begin{tabular}{|l|l|l|}
\hline Location & HS group & MACD group \\
\hline Buccal mucosa & $511(52.89 \%)$ & $361(50.2 \%)$ \\
\hline Lower alveolus & $217(22.46 \%)$ & $141(19.6 \%)$ \\
\hline Tongue & $144(14.09 \%)$ & $129(17.9 \%)$ \\
\hline $\begin{array}{l}\text { Maxilla \& upper } \\
\text { alveolus }\end{array}$ & $55(5.69 \%)$ & $45(6.25 \%)$ \\
\hline Larynx & $26(2.69 \%)$ & $20(2.78 \%)$ \\
\hline Lip & $8(0.82 \%)$ & $16(2.2 \%)$ \\
\hline Parotid & $3(0.3 \%)$ & $4(0.5 \%)$ \\
\hline Naso-orbital & $2(0.2 \%)$ & $3(0.41 \%)$ \\
\hline Total & 966 & 719 \\
\hline
\end{tabular}

Abbreviations: HS, hand-sewn; MACD, mechanical anastomotic coupler device.

Table 3 Flaps used in the study population

\begin{tabular}{|l|l|l|}
\hline Flap* & HS technique & MACD \\
\hline ALT & 547 & 395 \\
\hline Fibula & 240 & 191 \\
\hline RAFF & 180 & 105 \\
\hline MSAP & 2 & 22 \\
\hline PAP & 0 & 3 \\
\hline AMT & 3 & 3 \\
\hline Gracilis & 1 & 0 \\
\hline TFL & 2 & 0 \\
\hline Total & 975 & 719 \\
\hline
\end{tabular}

Abbreviations: ALT, anterolateral thigh flap; AMT, anteromedial thigh flap; MSAP, medial sural artery perforator flap; PAP, profunda artery perforator flap; RAFF, radial artery forearm flap. 
used veins were the common facial vein and its tributaries, IJV, and superior thyroid vein in either group (-Table 4). In the HS technique group, 748 (76.7\%) end-to-end and 227 (23.3\%) end-to-side venous anastomoses were performed. In the MACD group, 538 (74.8\%) end-to-end and 181 (25.2\%) end-to-side venous anastomoses were performed. The most commonly used coupler was $3 \mathrm{~mm}$ in size (42.4\%) (- Table 5). Flap re-exploration was done in 123 (12.6\%) patients in the HS technique group and 33 (4.58\%) in the MACD group.

Venous thrombosis was seen in $62(6.4 \%)$ patients in HS group and in $7(0.97 \%)$ patients in MACD group ( $p=0.000)$. The mean anastomosis time was shorter in MACD group ( $5 \pm$ 2 minutes) than the HS group ( $17 \pm 4$ minutes) $(p=0.0001)$. Twenty-five (2.56\%) patients had flap loss in HS group, whereas $4(0.55 \%)$ patients had flap loss in MACD group $(p=0.001)($-Table 6).

Table 4 Recipient veins and type of anastomosis in both groups

\begin{tabular}{|l|l|l|l|l|}
\hline \multirow{2}{*}{ Vein ${ }^{a}$} & \multicolumn{2}{|c|}{ HS technique } & \multicolumn{2}{c|}{ MACD } \\
\cline { 2 - 5 } & $\begin{array}{l}\text { End-to- } \\
\text { end }\end{array}$ & $\begin{array}{l}\text { End-to- } \\
\text { side }\end{array}$ & $\begin{array}{l}\text { End-to- } \\
\text { end }\end{array}$ & $\begin{array}{l}\text { End-to- } \\
\text { side }\end{array}$ \\
\hline CFV & 471 & 7 & 380 & 15 \\
\hline IJV and tributaries & 121 & 220 & 88 & $166^{\#}$ \\
\hline STV & 130 & 0 & 56 & 0 \\
\hline Lingual vein & 20 & 0 & 10 & 0 \\
\hline EJV & 6 & 0 & 4 & 0 \\
\hline Total & 748 & 227 & 538 & 181 \\
\cline { 2 - 6 } & \multicolumn{2}{|c|}{975} & & 719 \\
\hline
\end{tabular}

Abbreviations: CFV, common facial vein; EJV, external jugular vein; IJV, internal jugular vein; STV, superior thyroid vein.

${ }^{a}$ End-to-side anastomosis to IJV.

Table 5 Size of MACD used

\begin{tabular}{|l|l|l|}
\hline Size & No. of cases & $\%$ \\
\hline $2.0 \mathrm{~mm}$ & 28 & 3.9 \\
\hline $2.5 \mathrm{~mm}$ & 202 & 28.1 \\
\hline $3.0 \mathrm{~mm}$ & 305 & 42.4 \\
\hline $3.5 \mathrm{~mm}$ & 145 & 20.1 \\
\hline $4.0 \mathrm{~mm}$ & 39 & 5.5 \\
\hline Total & 719 & 100 \\
\hline
\end{tabular}

Table 6 Outcome comparison between HS technique and MACD

\begin{tabular}{|l|l|l|l|}
\hline Variable & $\begin{array}{l}\text { HS technique } \\
(\boldsymbol{n}=\mathbf{9 7 5})\end{array}$ & $\begin{array}{l}\text { MACD } \\
(\boldsymbol{n}=\mathbf{7 1 9})\end{array}$ & $p$ value \\
\hline Thrombosis & $62(6.4 \%)$ & $7(0.97 \%)$ & 0.000 \\
\hline $\begin{array}{l}\text { Anastomosis time } \\
\text { (min) }\end{array}$ & $17 \pm 4$ & $5 \pm 2$ & 0.0001 \\
\hline Flap loss & $25(2.56 \%)$ & $4(0.55 \%)$ & 0.001 \\
\hline
\end{tabular}

Abbreviations: HS, hand-sewn; MACD, mechanical anastomotic coupler device.

\section{Discussion}

Clinical applications of MACD are very well studied. ${ }^{6}$ Its applicability in developing countries is yet to be explored. Senthil Murugan et al published a randomized controlled trial and concluded that the outcome of the two groups was similar and MACD anastomosis was faster. ${ }^{7}$ However, the study was limited by a very small sample size.

There are many retrospective cohort studies and limited comparative studies between the two groups. We have made a comparison of our study with others in terms of multiple variables in -Table 7 . The venous thrombosis rate was $6.4 \%$ in the HS technique group and $0.97 \%$ in the MACD group. We did not find any difference in thrombosis rate in different sizes of MACD. The mean total anastomosis time was $17 \pm$ 4 minutes in the HS technique group and $5 \pm 2$ minutes in the MACD group. These results are comparable with others. The majority of the studies show a lesser incidence of thrombosis in the MACD group.

In patients with a recurrent disease, where both surgical and radiation therapy was given for primary disease, IJV was generally found to be very thick due to fibrosis. We prefer the HS technique for venous anastomosis in such cases. The thickened fibrosed wall is less pliable, and it is difficult to engage the vessel wall over the pins through the coupler rings. We did not encounter this problem with patients who underwent the only radiotherapy as primary treatment. Delacure et al had also reported similar findings in their study. ${ }^{8}$ The other scenario in which we preferred the HS technique was when we had donor vein diameter $<2 \mathrm{~mm}$ due to a higher incidence of thrombosis as mentioned earlier.

In our series, 411 (24.2\%) underwent an end-to-side anastomosis. We prefer to use IJV as a recipient in the unavailability of the common facial vein or its tributaries. The other reason is whenever there is a significant size discrepancy between the donor and the recipient veins, we preferred to do an end-to-side anastomosis to IJV. In the event of size discrepancy, we have to select the coupler size according to the smaller vein. For the larger vein, there is a risk of lumen compromise due to wall bunching within the coupler ring. However, Sullivan et al showed $100 \%$ patency rate by an end-to-end anastomosis with a size mismatch of 2 to 3.5:1. ${ }^{9}$ The time taken for anastomosis was 3 to 5 minutes. They attributed this benefit to MACD.

Several authors made an economic analysis of MACD usage. The anastomosis time is significantly reduced and hence the operation theater utility time. On average, authors had saved $£ 154$ and $\$ 234.89$ per coupler usage.,10 On the contrary, Senthil Murugan found that the MACD cost was not justified with a reduction in operation theater utility time. ${ }^{7}$ All three studies mentioned that the MACD was very cost-effective when it reduced the return to operation theater rates, as the incidence of venous thrombosis was significantly reduced. We could not make a similar economic analysis due to logistic issues.

Providing reconstructive surgical services in a high-volume tertiary oncologic center is challenging. Many 


\begin{tabular}{|c|c|c|c|c|c|c|c|c|c|c|c|c|c|c|}
\hline 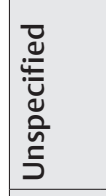 & & 1 & I & & 1 & 1 & 1 & 1 & $\begin{array}{l}\text { 垈 } \\
\text { L }\end{array}$ & 1 & $\stackrel{\infty}{\stackrel{\infty}{m}}$ & 1 & I & 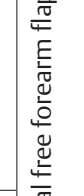 \\
\hline 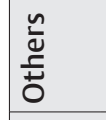 & & L & I & & !n & $r$ & 1 & $\mathscr{\wp}$ & 1 & $\bar{m}$ & 1 & 1 & $\stackrel{n}{m}$ & ثَ \\
\hline 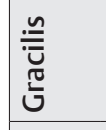 & & $F$ & I & & 1 & in & m & 1 & 1 & 1 & 1 & 1 & - & $\begin{array}{l}\frac{\grave{\omega}}{\bar{O}} \\
\bar{g} \\
\underline{u}\end{array}$ \\
\hline 言愛 & & $F$ & 1 & & 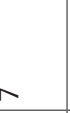 & $\begin{array}{l}\mathrm{O} \\
\text { m }\end{array}$ & $\stackrel{\mathscr{N}}{\underline{T}}$ & 1 & 1 & 1 & 1 & 1 & 1 & \\
\hline 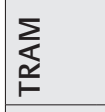 & & $\begin{array}{l}8 \\
\text { m }\end{array}$ & I & & $\stackrel{\infty}{\sim}$ & 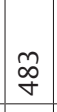 & 1 & 1 & 1 & $m$ & 1 & 1 & 1 & $\begin{array}{l}\text { 苞 } \\
\stackrel{\mathscr{U}}{E}\end{array}$ \\
\hline 9 & & $\bar{N}$ & 1 & & N & 1 & 1 & 1 & 1 & 1 & 1 & 1 & 1 & \\
\hline 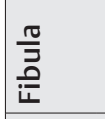 & & 옥 & 1 & & $\nabla$ & 1 & 1 & $\stackrel{\infty}{\wedge}$ & 1 & $\stackrel{\infty}{\stackrel{\infty}{n}}$ & 1 & 1 & $\bar{q}$ & $\frac{\bar{n}}{\frac{5}{0}}$ \\
\hline 安 & & Бू & 1 & & $\stackrel{\Delta}{\sim}$ & 1 & 1 & $\tilde{\sim}$ & 1 & $\stackrel{n}{\underline{0}}$ & 1 & 1 & รั & \\
\hline 片 & & 8 & 5 & & $v$ & 1 & 1 & 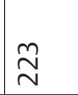 & 1 & $\stackrel{m}{m}$ & 1 & 1 & $\stackrel{\stackrel{\infty}{\infty}}{\sim}$ & \\
\hline . & $\underline{\underline{I}}$ & $\begin{array}{l}\text { ᄂ } \\
\text { ำ } \\
\llcorner\end{array}$ & 1 & & 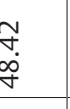 & 1 & $\bar{N}$ & $\mathscr{\vartheta}$ & 1 & I & 1 & $\begin{array}{l}\stackrel{\operatorname{Ln}}{\infty} \\
\infty \\
\end{array}$ & 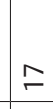 & \\
\hline$\underline{E F}$ & 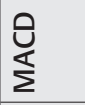 & $\begin{array}{l}\text { Ln } \\
亡 \\
\text { ம } \\
\end{array}$ & I & & ڤે & 1 & $\tilde{m}$ & $\stackrel{-}{\circ}$ & 1 & 1 & 1 & $\stackrel{?}{r}$ & in & 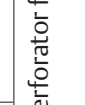 \\
\hline 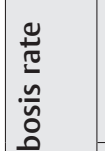 & $\begin{array}{l}\widehat{o} \\
\stackrel{5}{1} \\
\text { I }\end{array}$ & 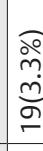 & نे & & סִ & 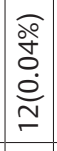 & 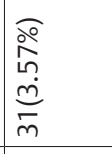 & $\begin{array}{l}\widehat{\circ} \\
\stackrel{0}{\infty} \\
\infty\end{array}$ & 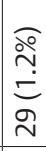 & 1 & 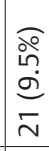 & $\stackrel{\circ}{\infty}$ & 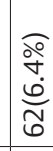 & 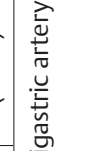 \\
\hline 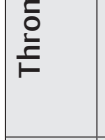 & $\stackrel{5}{\mathrm{o}}$ & 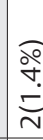 & वें & & 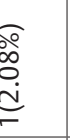 & \begin{tabular}{|l|}
$\widehat{\partial}$ \\
$\stackrel{0}{0}$ \\
$\stackrel{0}{\infty}$ \\
$\infty$
\end{tabular} & 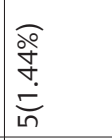 & 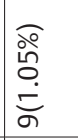 & 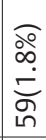 & 1 & 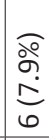 & 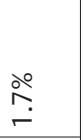 & 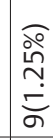 & . \\
\hline 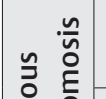 & $\underline{\underline{I}}$ & 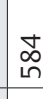 & $\lesssim$ & & 8 & $\begin{array}{l}m \\
\text { m }\end{array}$ & $\begin{array}{l}\infty \\
\infty \\
\infty\end{array}$ & $\infty$ & $\begin{array}{l}\infty \\
\infty \\
\sim \\
\sim\end{array}$ & ณ̂ & $\stackrel{\infty}{\sim}$ & tే & $\begin{array}{l}n \\
\sigma \\
\sigma\end{array}$ & \\
\hline $\begin{array}{ll}> & \frac{\pi}{5} \\
& \underset{\pi}{\pi}\end{array}$ & 导 & $\stackrel{m}{m}$ & $\stackrel{\rho}{m}$ & & $\stackrel{\infty}{+\infty}$ & 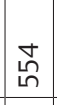 & $\frac{\sigma}{m}$ & 㫟 & 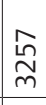 & $\stackrel{\infty}{m}$ & $\stackrel{N}{2}$ & 8 & $\frac{\sigma}{\pi}$ & 定 \\
\hline 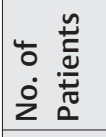 & & $\stackrel{\widetilde{N}}{N}$ & 5 & & $\underline{E}$ & f & \&્ & $\overline{8}$ & 过 & \begin{tabular}{|}
$\bar{\infty}$ \\
$\infty$
\end{tabular} & $\stackrel{\text { }}{\stackrel{m}{m}}$ & $\stackrel{\stackrel{\Xi}{\simeq}}{\square}$ & $\begin{array}{l}2 \\
\stackrel{\infty}{0} \\
\stackrel{0}{0}\end{array}$ & 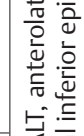 \\
\hline 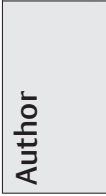 & & ثै & 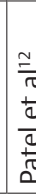 & & 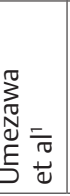 & 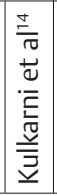 & 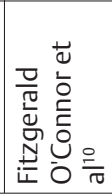 & 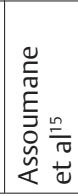 & 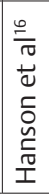 & 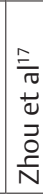 & 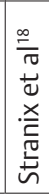 & 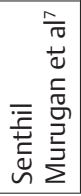 & 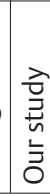 & 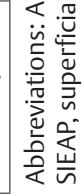 \\
\hline
\end{tabular}


times, the team needs to perform three to five free flaps in a day. In such circumstances, MACD usage reduces the surgeon's strain to perform a venous anastomosis. In addition to this, performing an end-to-side anastomosis is much easier than an HS technique. The other advantages are a short learning period and easy application even in deep surgical spaces. General microsurgical principles are the same for couplers also. Judging and selecting the appropriate size of the coupler ring for the anastomosis is crucial. If the size of the anastomotic ring is larger than the size of the chosen vein, it may cause tearing of the venous wall when attempted to accommodate the wall of the vein to pins. On the other hand, if the smaller sized ring is chosen, it leads to pleating or crowding of the venous wall. Both circumstances may lead to anastomotic failure. Heparinized saline is used to flush the anastomotic site to prevent clot formation. The vessel wall has to be evenly distributed on the coupler pins. Twisting and kinking of the pedicle is avoided while fixing the edges of the vessel wall to the coupler rings. Tension at the anastomotic site is also avoided.

We opine that one has to master the HS technique before using MACD. In several situations as described above, we might need to perform HS anastomosis. It is also preferable to use the HS technique for smaller diameter venous anastomosis $(<2 \mathrm{~mm})$.

The limitations of the study are a retrospective study design and lack of economic analysis.

\section{Conclusion}

MACD is an effective alternative for the HS technique for venous anastomosis. There is a significant reduction in anastomosis time, flap loss, and return to operation theater due to venous thrombosis. MACD reduces the surgeon's strain, especially in a high-volume center. Prospective randomized studies including an economic analysis are required to ascertain the cost-effectiveness of coupler devices.

\section{Conflicts of Interest}

None declared.

\section{References}

1 Gabrysz-Forget F, Tabet P, Rahal A, Bissada E, Christopoulos A, Ayad T. Free versus pedicled flaps for reconstruction of head and neck cancer defects: a systematic review. J Otolaryngol Head Neck Surg 2019;48(1):13

2 Copelli C, Tewfik K, Cassano L, et al. Management of free flap failure in head and neck surgery. Acta Otorhinolaryngol Ital 2017;37(5):387-392

3 Maruccia M, Fatigato G, Elia R, et al. Microvascular coupler device versus hand-sewn venous anastomosis: A systematic review of the literature and data meta-analysis. Microsurgery 2020;40(5):608-617

4 Head LK, McKay DR. Economic comparison of hand-sutured and coupler-assisted microvascular anastomoses. J Reconstr Microsurg 2018;34(1):71-76

5 Ruiz-Cases A, Salmerón-González E, Pérez-García A, Esteban-Vico JR, García-Vilariño E. Smaller diameter anastomotic coupling devices have higher rates of venous thrombosis in microvascular free tissue transfer. Plast Reconstr Surg 2018;142(3):417e-418e

6 Zhu Z, Wang X, Huang J, et al. Mechanical versus hand-sewn venous anastomoses in free flap reconstruction: a systematic review and meta-analysis. Plast Reconstr Surg 2018;141(5):1272-1281

7 Senthil Murugan M, Ravi P, Mohammed Afradh K, Tatineni V, Krishnakumar Raja VB. Comparison of the efficacy of venous coupler and hand-sewn anastomosis in maxillofacial reconstruction using microvascular fibula free flaps: a prospective randomized controlled trial. Int J Oral Maxillofac Surg 2018;47(7):854-857

8 DeLacure MD, Kuriakose MA, Spies AL. Clinical experience in end-to-side venous anastomoses with a microvascular anastomotic coupling device in head and neck reconstruction. Arch Otolaryngol Head Neck Surg 1999;125(8):869-872

9 Sullivan SK, Dellacroce F, Allen R. Management of significant venous discrepancy with microvascular venous coupler. J Reconstr Microsurg 2003;19(6):377-380

10 Fitzgerald O'Connor E, Rozen WM, Chowdhry M, et al. The microvascular anastomotic coupler for venous anastomoses in free flap breast reconstruction improves outcomes. Gland Surg 2016;5(2):88-92

11 Yap LH, Constantinides J, Butler CE. Venous thrombosis in coupled versus sutured microvascular anastomoses. Ann Plast Surg 2006;57(6):666-669

12 Patel SA, Pang JH, Natoli N, Gallagher S, Topham N. Reliability of venous couplers for microanastomosis of the venae comitantes in free radial forearm flaps for head and neck reconstruction. J Reconstr Microsurg 2013;29(7):433-436

13 Umezawa H, Ogawa R, Nakamizo M, Yokoshima K, Hyakusoku H. A comparison of microsurgical venous anastomosis techniques. J Nippon Med Sch 2015;82(1):14-20

14 Kulkarni AR, Mehrara BJ, Pusic AL, et al. Venous thrombosis in handsewn versus coupled venous anastomoses in 857 consecutive breast free flaps. J Reconstr Microsurg 2016;32(3):178-182

15 Assoumane A, Wang L, Liu K, Shang ZJ. Use of couplers for vascular anastomoses in 601 free flaps for reconstruction of defects of the head and neck: technique and two-year retrospective clinical study. Br J Oral Maxillofac Surg 2017;55(5):461-464

16 Hanson SE, Mitchell MB, Palivela N, et al. Smaller diameter anastomotic coupling devices have higher rates of venous thrombosis in microvascular free tissue transfer. Plast Reconstr Surg 2017;140(6):1293-1300

17 Zhou W, Zhang WB, Yu Y, et al. Risk factors for free flap failure: a retrospective analysis of 881 free flaps for head and neck defect reconstruction. Int J Oral Maxillofac Surg 2017;46(8):941-945

18 Stranix JT, Rifkin WJ, Lee ZH, et al. Comparison of hand-sewn versus coupled venous anastomoses in traumatic lower extremity reconstruction. J Reconstr Microsurg 2019;35(1):31-36 